\title{
Papers
}

\section{First hundred cases of variant Creutzfeldt-Jakob disease: retrospective case note review of early psychiatric and neurological features}

\author{
Michael D Spencer, Richard S G Knight, Robert G Will
}

\begin{abstract}
Objective To describe the early psychiatric and neurological features of variant Creutzfeldt-Jakob disease.

Design Cohort study.

Setting National surveillance system for

Creutzfeldt-Jakob disease in the United Kingdom.

Participants The first 100 cases of variant

Creutzfeldt-Jakob disease identified in the United

Kingdom.

Main outcome measures The timing and nature of early psychiatric and neurological symptoms in variant Creutzfeldt-Jakob disease.

Results The early stages of variant Creutzfeldt-Jakob disease are dominated by psychiatric symptoms, but neurological symptoms precede psychiatric symptoms in $15 \%$ of cases and are present in combination with psychiatric symptoms in 22\% of cases from the onset of disease. Common early psychiatric features include dysphoria, withdrawal, anxiety, insomnia, and loss of interest. No common early neurological features exist, but a significant proportion of patients do exhibit neurological symptoms within 4 months of clinical onset, including poor memory, pain, sensory symptoms, unsteadiness of gait, and dysarthria.

Conclusions Although the diagnosis of variant Creutzfeldt-Jakob disease may be impossible in the early stages of the illness, particular combinations of psychiatric and neurological features may allow early diagnosis in an appreciable proportion of patients.
\end{abstract}

\section{Introduction}

A new variant of Creutzfeldt-Jakob disease was first reported in 1996, ${ }^{1}$ and compelling evidence now exists that this novel disease is caused by exposure of humans to the agent that causes bovine spongiform encephalopathy. The initial description of variant Creutzfeldt-Jakob disease- based on the first 10 cases diagnosed-reported a predominantly psychiatric initial presentation, as distinct from the usual clinical course of sporadic Creutzfeldt-Jakob disease.

A study of the first 14 cases of variant CreutzfeldtJakob disease in the United Kingdom, of which 13 patients had been seen by a psychiatrist early in the clinical course, revealed that all 14 patients had early psychiatric features. ${ }^{2}$ Typical presentations were depression, anxiety, and behavioural change, and two patients displayed first rank psychotic symptoms. However, the authors concluded that analysis of the psychiatric symptoms did not reveal specific features that differentiated variant Creutzfeldt-Jakob disease, at the time of presentation, from more common psychiatric disorders, although subsequent neurological and cognitive deterioration led to the eventual clinical suspicion of Creutzfeldt-Jakob disease. These psychiatric features concur with those described in subsequent case reports, ${ }^{34}$ and with an analysis published in the Psychiatric Bulletin. ${ }^{5}$

Subsequent to the description of the first 14 cases of variant Creutzfeldt-Jakob disease in $1997,{ }^{2}$ the number of definite or probable cases in the United Kingdom has increased to over 100 (data supplied by National CJD Surveillance Unit, Edinburgh). Scope now exists for a much larger analysis of this relatively newly described condition and, in particular, an assessment of the early psychiatric and neurological features.

We report on a retrospective analysis of case records held in the National CJD Surveillance Unit relating to the first 100 patients who have been diagnosed with variant Creutzfeldt-Jakob disease according to established diagnostic criteria. ${ }^{6}$ The importance of providing a detailed analysis of the early diagnostic features of variant Creutzfeldt-Jakob disease is underlined by the occurrence of this condition in countries other than the United Kingdom, including France, Ireland, and Italy, with the possibility that the risks of human exposure to the bovine spongiform encephalopathy agent may be even more widespread.

\section{Methods}

We used all case note material held in the archives of the National CJD Surveillance Unit relating to the first 100 patients diagnosed by the unit as having variant Creutzfeldt-Jakob disease. This comprised 98 unit questionnaires, 82 sets of general practitioner notes, 89 sets of hospital notes, and 100 sets of correspondence between specialists and general practitioners. A multicentre research ethics committee approved the study.

We recorded the occurrence of psychiatric and neurological features by applying a standardised protocol for the examination of case note material,
Department of
Psychiatry, Box 189,
Addenbrooke's
Hospital,
Cambridge
CB2 2QQ
Michael D Spencer
research fellow
National CJD
Surveillance Unit,
Western General
Hospital, Edinburgh
EH4 2XU
Richard S G Knight
consultant neurologist
Robert G Will
professor of clinical
neurology
Correspondence to:
Robert G Will
r.g.will@ed.ac.uk
BMJ 2002;324:1479-82 
listing every psychiatric and neurological sign and symptom, and then clustering together clinically similar features. We listed cognitive features separately but have included them in the analysis as psychiatric features in this paper for the sake of simplicity. For every feature, we recorded the time between onset of illness and first appearance of the particular feature (in months, to the nearest half month) and calculated the median time to development of the feature, together with upper and lower quartiles.

In order to provide information on the likelihood of features occurring with time we carried out an analysis of the frequency of specific features and their time to development. We classified features occurring within four months of onset as "early," features

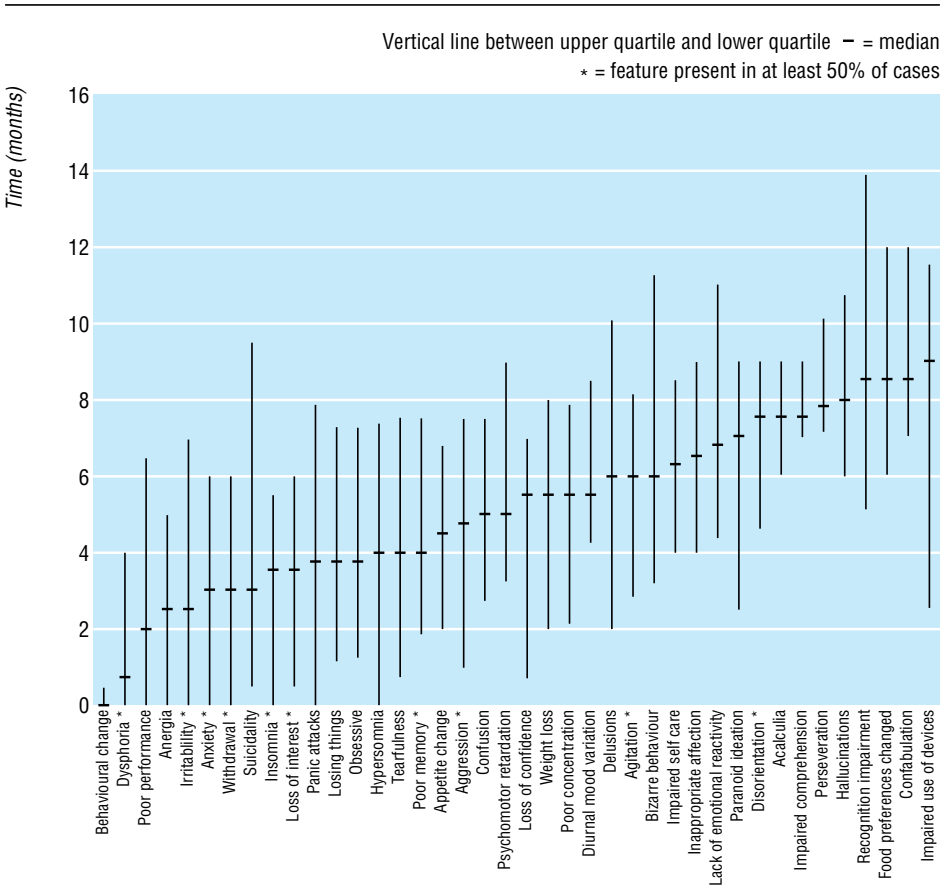

Fig 2 Times of onset of psychiatric features (in months)

Table 1 Analysis of psychiatric features according to frequency and median time of onset

\begin{tabular}{|c|c|c|c|}
\hline Psychiatric features & $\begin{array}{l}\text { Early onset } \\
\text { ( }<4 \text { months) }\end{array}$ & $\begin{array}{l}\text { Later onset } \\
\text { ( } 4 \text { to }<6 \text { months) }\end{array}$ & $\begin{array}{l}\text { Late onset } \\
\text { ( } \geqslant 6 \text { months) }\end{array}$ \\
\hline Common $(n \geqslant 50)$ & $\begin{array}{l}\text { Dysphoria } \\
\text { Withdrawal } \\
\text { Anxiety } \\
\text { Irritability } \\
\text { Insomnia } \\
\text { Loss of interest }\end{array}$ & $\begin{array}{l}\text { Poor memory } \\
\text { Impaired concentration } \\
\text { Aggression }\end{array}$ & $\begin{array}{l}\text { Disorientation } \\
\text { Agitation }\end{array}$ \\
\hline $\begin{array}{l}\text { Less common } \\
\qquad(\mathrm{n}=25-<50)\end{array}$ & $\begin{array}{l}\text { Behavioural change } \\
\text { Anergia } \\
\text { Poor performance }\end{array}$ & $\begin{array}{l}\text { Tearfulness } \\
\text { Weight loss } \\
\text { Appetite change } \\
\text { Hypersomnia } \\
\text { Confusion }\end{array}$ & $\begin{array}{l}\text { Hallucinations } \\
\text { Impaired self care } \\
\text { Paranoid delusions } \\
\text { Inappropriate affect }\end{array}$ \\
\hline Rare $(n<25)$ & $\begin{array}{l}\text { Obsessive features } \\
\text { Losing things } \\
\text { Suicidal ideation } \\
\text { Panic attacks }\end{array}$ & $\begin{array}{l}\text { Psychomotor retardation } \\
\text { Diurnal mood variation } \\
\text { Loss of confidence }\end{array}$ & $\begin{array}{l}\text { Bizarre behaviour } \\
\text { Paranoid ideation } \\
\text { Recognition impairment } \\
\text { Confabulation } \\
\text { Lack of emotion } \\
\text { Perseveration } \\
\text { Impaired comprehension } \\
\text { Change in eating } \\
\text { preferences } \\
\text { Impaired use of devices } \\
\text { Acalculia }\end{array}$ \\
\hline
\end{tabular}

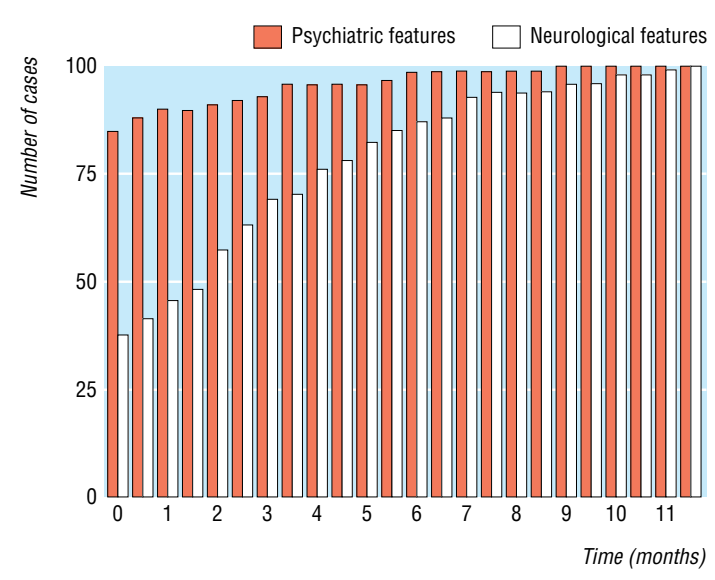

Fig 1 Cumulative onset of psychiatric and neurological features

occurring between four and six months as "later," and those occurring after six months as "late." We classified features affecting at least $50 \%$ of patients as "common," those affecting between $25 \%$ and $50 \%$ of patients as "less common," and those affecting less than $25 \%$ of patients as "rare."

\section{Results}

The median age at onset for all 100 patients was 26 (range 12-74) years. Excluding one patient still alive, the median duration of illness was 13.0 (6-39) months. Of the 100 patients, 63 had been seen by a psychiatrist during the course of the illness. Most patients were first referred to a psychiatrist (38), neurologist (30), or general physician (21), although a minority were initially referred to other specialties-orthopaedics (3), ear, nose, and throat surgery (2), paediatrics (2), maxillofacial surgery (2), rheumatology (1), and general surgery (1). (In this analysis, we classified child psychiatrists and paediatric neurologists as psychiatrists and neurologists, rather than in separate categories.)

The median time from onset was 0 months until occurrence of the first psychiatric symptom and two months until occurrence of the first neurological symptom; 57 patients had at least one neurological symptom within two months of clinical onset. The times of onset of psychiatric and neurological features for all 100 cases are displayed cumulatively in fig 1 and for each feature in fig 2 and fig 3. Psychiatric features preceded neurological features in 63 cases, whereas neurological features preceded psychiatric features in 15 cases. In the remaining 22 cases both psychiatric and neurological features were present from onset.

Tables 1 and 2 show all psychiatric and neurological features categorised by time of onset and frequency of occurrence. Common early psychiatric features included dysphoria, withdrawal, anxiety, irritability, insomnia, and loss of interest. No common early neurological features existed. Less common early psychiatric features were behavioural change, anergia, and poor performance, and a minority of cases exhibited pain as an early neurological feature. Later features included poor memory, aggression, and tearfulness in combination with gait disturbance, dysarthria, and sensory symptoms. Disorientation, hallucinations, 
paranoid ideation, confabulation, impaired self care, and most neurological features, including involuntary movements, developed late in the course of the illness.

\section{Discussion}

The early clinical features of variant Creutzfeldt-Jakob disease described in this paper are consistent with previous descriptions, ${ }^{2-5}$ but the systematic analysis of a much larger number of cases than in the past provides a much more detailed picture of the clinical phenotype and the variations that can occur. The early stages of variant Creutzfeldt-Jakob disease are dominated by psychiatric features. However, neurological features precede psychiatric symptoms in $15 \%$ of cases, are present in combination with psychiatric symptoms in $22 \%$ of cases at onset, and occur in $57 \%$ of cases within two months of the first symptom. Although early recognition of an underlying neurological disorder may be impossible in many cases, the dissemination of detailed information on the early psychiatric and neurological features of variant Creutzfeldt-Jakob disease may aid earlier diagnosis, particularly in patients with combinations of psychiatric and neurological symptoms.

\section{Methodology}

An important objective of this study has been the estimation of the timing of the occurrence of a range of features in relation to disease onset. The timing of onset of first symptoms in each case was defined in advance of this study by consensus review by two consultant neurologists of data held at the unit. It is possible that individual psychiatric or neurological features may not have been recorded or that the timing of development of these features in case records may reflect the timing of observation rather than the true time a feature first occurred. Information was obtained from multiple sources, including unit questionnaires with a history obtained directly from relatives and sometimes patients, general practitioner records, hospital notes, and correspondence between hospital and general practitioners. In the great majority of cases information was available from all these sources, and it is likely that relatively accurate estimates have been made. For late features such as time to becoming mute or bed bound the records were less reliable and these features have not been included in the analysis.

\section{Referral pattern}

The predominantly psychiatric symptoms in the earlier stages of variant Creutzfeldt-Jakob disease are mirrored in the patterns of referral to specialists- $63 \%$ of patients were seen by a psychiatrist at some stage, and the most frequent initial referral specialty was also psychiatry in $38 \%$ of cases. However, the heterogeneous early features resulted in initial referral to neurologists or physicians in an appreciable proportion of cases and to paediatricians or paediatric neurologists in a minority, reflecting the six patients in whom clinical onset occurred at less than 16 years of age. Referral to specialties such as orthopaedics, rheumatology, or maxillofacial surgery was linked to the small minority of patients with pain or sensory symptoms as the initial symptom.

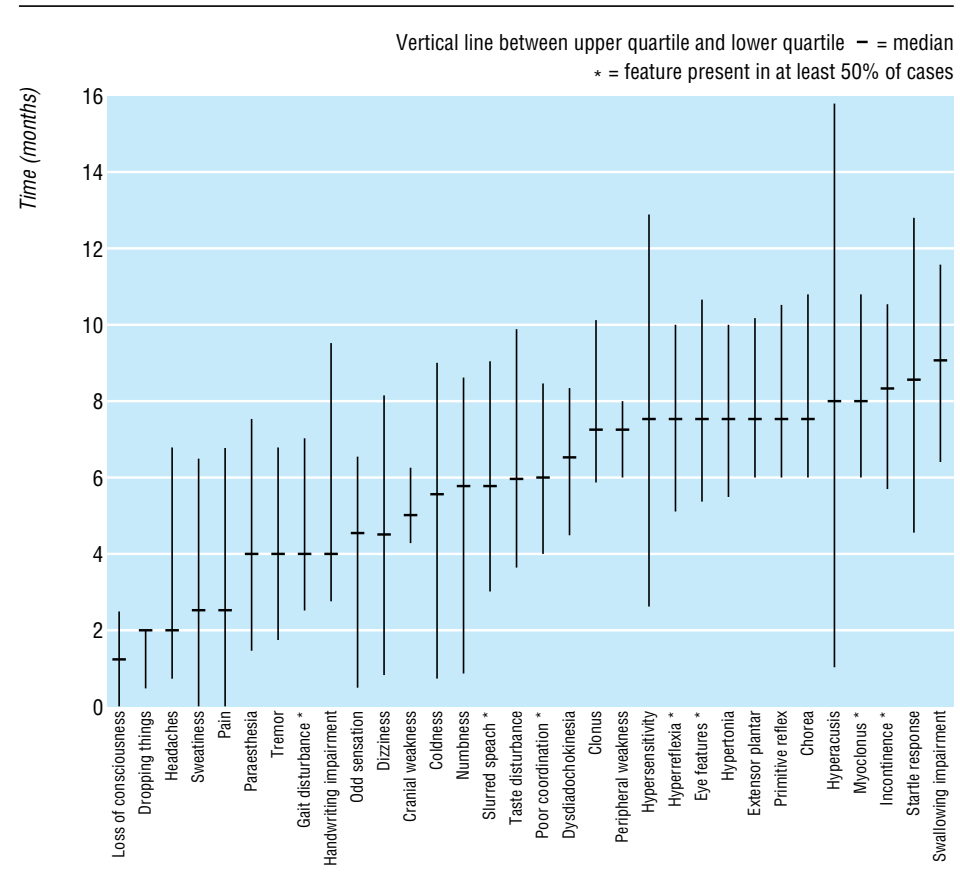

Fig 3 Times of onset of neurological features (in months)

\section{Clinical features}

The psychiatric symptoms described in this series are similar to previous descriptions..$^{2-5}$ Common early affective symptoms included dysphoria, anergia, loss of interest, insomnia, anxiety, and withdrawal, leading to a diagnosis of depression in many cases, but a minority of cases also developed psychotic features such as auditory or visual hallucinations and paranoid behaviour or delusions. Many patients became agitated or aggressive, sometimes causing difficulties in management, but suicidal ideation was rare $(9 \%$ of cases), and there was no record of deliberate self harm in any case. Fleeting delusions were described as an unusual psychiatric feature in earlier reports ${ }^{25}$ and, although clearly a feature in some cases, were relatively rare in comparison with the frequency of other more obvious psychiatric symptoms. The possibility of an underlying neurological disorder was raised in many

Table 2 Analysis of neurological features according to frequency and median time of onset

\begin{tabular}{|c|c|c|c|}
\hline $\begin{array}{l}\text { Neurological } \\
\text { features }\end{array}$ & $\begin{array}{l}\text { Early onset } \\
\text { ( }<4 \text { months) }\end{array}$ & $\begin{array}{l}\text { Later onset } \\
\text { ( } 4 \text { to }<6 \text { months) }\end{array}$ & $\begin{array}{l}\text { Late onset } \\
\text { ( } \geqslant 6 \text { months) }\end{array}$ \\
\hline Common $(n \geqslant 50)$ & None & $\begin{array}{l}\text { Gait disturbance } \\
\text { Slurring of speech }\end{array}$ & $\begin{array}{l}\text { Hyperreflexia } \\
\text { Impaired coordination } \\
\text { Myoclonus } \\
\text { Incontinence } \\
\text { Eye features }\end{array}$ \\
\hline $\begin{array}{r}\text { Less common } \\
(\mathrm{n}=25-<50)\end{array}$ & Pain & $\begin{array}{l}\text { Paraesthesia } \\
\text { Numbness }\end{array}$ & $\begin{array}{l}\text { Chorea } \\
\text { Extensor plantar } \\
\text { responses } \\
\text { Swallowing impairment } \\
\text { Clonus } \\
\text { Hypertonia } \\
\text { Primitive reflexes }\end{array}$ \\
\hline Rare $(n<25)$ & $\begin{array}{l}\text { Headaches } \\
\text { Dropping things } \\
\text { Sweatiness } \\
\text { Loss of consciousness }\end{array}$ & $\begin{array}{l}\text { Tremor } \\
\text { Handwriting impairment } \\
\text { Coldness } \\
\text { Odd sensation } \\
\text { Dizziness } \\
\text { Cranial motor weakness }\end{array}$ & $\begin{array}{l}\text { Dysdiadochokinesia } \\
\text { Taste disturbance } \\
\text { Startle response } \\
\text { Hypersensitivity } \\
\text { Peripheral motor } \\
\text { weakness } \\
\text { Hyperacusis }\end{array}$ \\
\hline
\end{tabular}


cases by the development of cognitive impairment, including poor memory, impaired concentration, disorientation, or, in a minority, frank confusion. These features developed a median of 4-7.5 months from clinical onset, although in a small minority of cases they were present from the earliest stages.

Affective psychiatric symptoms were common in the early stages, but no common early neurological features existed, a finding consistent with previous reports. $^{25}$ The most common early neurological feature was pain not associated with sensory symptoms; this was persistent and unpleasant and often affected the limbs, trunk, or face. Between a median of four and six months common neurological features included gait disturbance, often in the form of minor unsteadiness, and dysarthria. Paraesthesia and numbness in a similar distribution to and often associated with pain also occurred at a median of 4-6 months and affected nearly half of the patients. ${ }^{7}$ The combination of a psychiatric disorder with affective or psychotic features and persistent pain, dysarthria, gait ataxia, or sensory symptoms should at least raise the suspicion of variant Creutzfeldt-Jakob disease, particularly if this is combined with any suggestion of cognitive impairment. Some of the neurological features, such as sensory symptoms, unsteadiness of gait, and dysarthria, may occur in psychiatric conditions or as side effects of psychotropic drugs, but the persistence of these symptoms and the evolution of additional neurological symptoms may indicate that variant Creutzfeldt-Jakob disease is a potential diagnosis.

The analyses in this paper indicate that suggestive neurological features of variant Creutzfeldt-Jakob disease such as cerebellar signs, involuntary movements (myoclonus, chorea, or dystonia), upper motor neurone signs, and visual symptoms are very common but develop relatively late in the course of the illness. Psychiatric symptoms indicating the likelihood of an organic aetiology-for example, disorientation, hallucinations, and impaired self care-also occur late. When the diagnosis of variant Creutzfeldt-Jakob disease is suspected patients should be referred for investigation to a neurological centre. ${ }^{6}$

\section{Conclusion}

Although variant Creutzfeldt-Jakob disease is a very rare disease, mathematical analyses taking account of changes in time to referral and diagnostic confirmation indicate an increase in the number of cases with time. ${ }^{8}$ The possibility of a large epidemic of variant Creutzfeldt-Jakob disease cannot be excluded. Doctors may also see patients who are worried about the possibility of this diagnosis. We hope that the detailed analysis of the early psychiatric and neurological features of variant Creutzfeldt-Jakob disease in this paper may help with early and accurate recognition of this condition.

This study would not have been possible without the data collected by research staff at the National CJD Surveillance Unit (M Zeidler, G Stewart, M A Macleod, C Henry, A Lowman) and the cooperation of the relatives of patients with variant Creutzfeldt-Jakob disease. We thank clinicians throughout the United Kingdom for referring suspect cases and allowing data to be collected and D Everington for statistical advice.

Contributors: MDS, RSGK, and RGW initiated the study and formulated the methods. MDS reviewed case notes, extracted

\section{What is already known on this topic}

The early stages of variant Creutzfeldt-Jakob disease are dominated by psychiatric symptomatology

Some patients have early neurological features that might suggest the presence of an underlying neurological disorder

\section{What this study adds}

This study provides a comprehensive description of the evolution of psychiatric and neurological features in variant Creutzfeldt-Jakob disease

An appreciable proportion of patients have early neurological symptoms

A high proportion of patients have a combination of psychiatric and neurological features within four months of clinical onset that suggest the diagnosis of variant Creutzfeldt-Jakob disease

data, and compiled tables of psychiatric and neurological features. RGW and RSGK reviewed the data and suggested further analyses. All authors contributed to writing and redrafting the paper. RGW is the guarantor.

Funding: MDS carried out this work under the tenure of a research $\mathrm{SHO}$ post on the Cambridge psychiatry training rotation. The project was funded by the Department of Health. The views expressed are those of the authors.

Competing interests: None declared.

1 Will RG, Ironside JW, Zeidler M, Cousens SN, Estibeiro K, Alperovitch A, et al. A new variant of Creutzfeldt-Jakob disease in the UK. Lancet 1996;347:921-5.

2 Zeidler M, Johnstone EC, Bamber RW, Dickens CM, Fisher CJ, Francis AF, et al. New variant Creutzfeldt-Jakob disease: psychiatric features. Lancet 1997;350:908-10.

3 Allroggen H, Dennis G, Abbottt RJ, Pye IF. New-variant Creutzfeldt-Jakob disease: three case reports from Leicestershire. J Neurol Neurosurg Psychiatry 2000; 68:375-8.

4 Dervaux A, Vicart S, Lopes F, Le Borgne M-H. Psychiatric features of vCJD similar in France and UK. Br J Psychiatry 2001;178:276.

5 Will RG, Stewart G, Zeidler M, Macleod MA, Knight RSG. Psychiatric features of new variant Creutzfeldt-Jakob disease. Psychiatric Bull 1999;23:264-7.

6 Will RG, Zeidler M, Stewart GE, Macleod MA, Ironside JW, Cousens SN, et al. Diagnosis of new variant Creutzfeldt-Jakob disease. Ann Neurol 2000;47:575-82.

7 Macleod MA, Knight R, Stewart G, Zeidler M, Will R. Sensory features of variant Creutzfeldt-Jakob disease. I Neurol Neurosurg Psychiatry 2000;69:413-4.

8 Andrews NJ, Farrington CP, Cousens SN, Smith PG, Ward H, Knight RSG, et al. Incidence of variant Creutzfeldt-Jakob disease in the UK. Lancet 2000;356:481-2.

(Accepted 29 May 2002)

\section{Endpiece \\ Sean O'Casey on surgeons}

It's wonderful what a lot of things a man can do without, accordin' to the doctors.

Some of the buggers would give up the spendin' of the first night with a lovely woman he was after marryin' for a half hour's hackin' at a man.

Sean O'Casey, Autobiographies 1. New York: Carrol and Graf, 1984. 